\title{
Strain Mode Dependence of Deformation Texture Developments: Microstructural Origin
}

\author{
S. RAVEENDRA, A.K. KANJARLA, H. PARANJAPE, S.K. MISHRA, S. MISHRA, \\ L. DELANNAY, I. SAMAJDAR, and P. VANHOUTTE
}

Fully recrystallized commercial-purity aluminum sheets were deformed by limiting dome height tests, the following strain modes: uniaxial tension (US), near plane strain tension (PS), and equibiaxial tension (BS) were identified using standard procedure. The deformation texture developments differed significantly depending on the strain mode. Although the full constraints Taylor (FCT) model captured the texture developments in US, it failed to reproduce deformation textures in PS and especially in BS. The Advanced LAMEL (ALAMEL) model and the crystal plasticity finite element method (CPFEM) were, however, successful with respect to all three strain modes. Microtexture data brought out interesting observations of orientation gradients. First, the orientation gradients increased from US to PS to BS. Second, such gradients were mostly around initial (or prior deformation) grain boundary regions. A simple algorithm, and an associated computer program, was developed to demarcate such near boundary gradient zones (NBGZs). The area fraction and severity of NBGZ seemed to affect the texture development; FCT was reasonably successful at low NBGZ, whereas high NBGZ required the ALAMEL and the CPFEM models that are capable of addressing strain heterogeneity and grain interactions.

DOI: $10.1007 / \mathrm{s} 11661-010-0580-0$

(c) The Minerals, Metals \& Materials Society and ASM International 2010

\section{INTRODUCTION}

PLASTIC deformation in metallic materials often is studied either from the classical crystal plasticity ${ }^{[1-24]}$ or from the perspective of microstructure developments. ${ }^{[25-56]}$ The former tend to focus on the requirement of stress equilibrium and strain compatibility of adjacent grains and its effect on plastic anisotropy, whereas the latter involve topics ranging from substructure developments to dislocation interactions. Arguably, both are important and interrelated. It is, however, fair to admit that the two approaches have been used rarely, in reasonable conjunction, for common scientific goals.

As an example, let us consider predictions of deformation textures. All texture prediction models are based on crystal plasticity. They describe plastic deformation

S. RAVEENDRA, formerly Research Scholar at Indian Institute of Technology Bombay, Mumbai 400076, India, is now Research Engineer at Sandvik Asia Pvt. Ltd., Pune 411012, India. A.K. KANJARLA, formerly Doctoral Student at KU Leuven, BE-3001 Leuven, Belgium, is now Postdoctoral Researcher at Los Alamos National Laboratory, P.O. Box 1663, Los Alamos, NM 87545. H. PARANJAPE, formerly B. Tech Student at Indian Institute of Technology Bombay, is now Graduate Research Associate at The Ohio State University, Columbus, OH 43210. S.K. MISHRA, formerly Research Scholar at Indian Institute of Technology Bombay, is now Researcher at General Motors R\&D, Bangalore 560002, India. S. MISHRA, Assistant Professor, is with the Indian Institute of Technology Bombay. L. DELANNAY, Professor, is with the Université Catholique de Louvain (UCL), BE-1348 Louvain-la-Neuve, Belgium. I. SAMAJDAR, Professor, is with the Indian Institute of Technology Bombay. Contact e-mail: indra@iitb.ac.in P. VAN HOUTTE, Professor, is with KU Leuven.

Manuscript submitted July 7, 2010.

Article published online January 4, 2011 of a crystallite or part of a crystallite by relating velocity gradient tensors, slip rates, lattice rotation rates, and deviatoric stress. In the full constraint Taylor (FCT) model, ${ }^{[1,10,25]}$ the velocity gradient tensor is homogenous. This is, of course, in conflict with microstructural observations of strain heterogeneities and geometrically necessary boundaries. ${ }^{[27-29]}$ The subsequent relaxed constraint models offer "limited" strain heterogeneity, involving only certain components of velocity gradient tensor. Although relaxed constraint models led to improvements in deformation texture prediction, the choice of the type of relaxation is, at best, artificial. The classical full and relaxed constraints models are often termed "one-point" - taking, at a time, a single grain in account. An extension is possible through generalized relaxed constraints ${ }^{[10]}$ and viscoplastic self-consistent ${ }^{[10,22,23,57]}$ methods, which are "one-point' models taking the macroscopic polycrystal properties into account. These "one-point" models do not consider interactions among neighboring grains. The multipoint models, however, consider two or more grains interacting with each other as a statistical volume element at the mesoscale. Even more accurate solutions exist through so-called full-field numerical approaches such as crystal plasticity based finite element method (CPFEM) ${ }^{[14-16,24]}$ or the fast Fourier transform (FFT) method. ${ }^{[20]}$ These methods are typically computation intensive but can qualitatively capture the strain heterogeneities and the orientation gradients in a microstructure. The "multipoint" models, however, incorporate grain interactions and resulting heterogeneity in a simplified way. It is usually acknowledged that "multipoint" models as well as finite element and the FFT methods offer better 
predictability for deformation textures because they can simultaneously satisfy stress equilibrium and strain compatibility requirements.*

*Both are "first principles" of physics and mechanics and have absolute validity.

It, however, needs to be noted the typical multipoint models are at least approximately two to three times faster, computationally, than the full-field numerical approaches such as CPFEM.

In this study, commercial purity aluminum sheets were deformed to different strain levels and strain modes. This process induced significant differences in the developments of crystallographic texture and microstructure. The results were used to test several deformation texture models. The deformed microstructures were studied to bring out possible signatures of grain interactions and to relate the same with apparent predictabilities of deformation texture simulations.

\section{EXPERIMENTAL METHODS}

Fully recrystallized $(\approx 30-\mu \mathrm{m}$ average grain size $)$ commercial AA1050 alloy sheets, of 1-mm thickness, were subjected to limiting dome height tests (LDH) in a 200 -ton, double-action hydraulic press. The reader may refer elsewhere for the alloy composition ${ }^{[58,59]}$ as well as for different sheet geometries ${ }^{[58-60]}$ used to exert different strain modes. Figure 1 shows the experimental forming limit curve (FLC), identifying the safe and unsafe

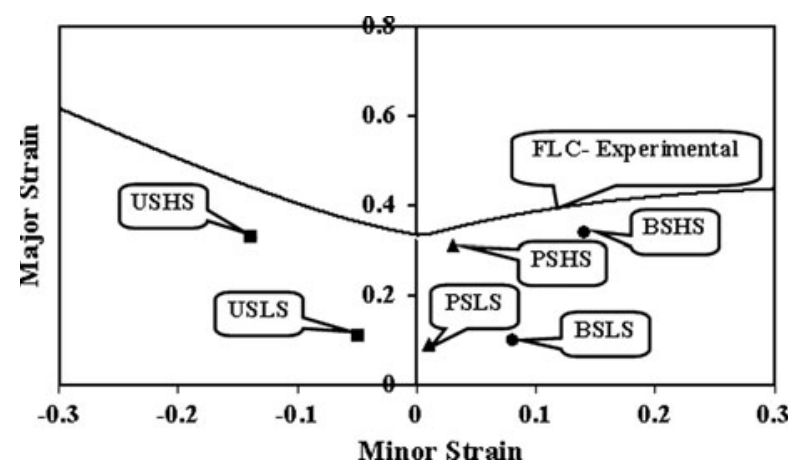

Fig. 1-Experimental FLC obtained from LDH tests. Samples were selected based on the following different strain modes: US, PS, and BS. Two samples, from the respective strain paths, were taken. These samples had nearly equivalent strains and generalized as LS and HS strain, respectively. (failed) regions of sheet metal forming. A range of strains and strain modes were identified using the standard procedure. ${ }^{[61]}$ From these, samples corresponding to three strain modes (uniaxial tension [US], near plane strain tension [PS], and equibiaxial tension [BS]) and two strain levels (low [LS] and high [HS] von Mises effective strains) were selected (Tables I and II). It should be noted that all strain modes tend to rotate, at large strains, toward plane strain. This effect is more apparent (Figure 1) in PS strain and BS than in US tension. Compared with the experimental FLC, USHS had a lower strain than PSHS and BSHS.

The deformed samples were electropolished using standard procedure ${ }^{[62]}$ and then were subjected to X-ray texture and microtexture/microstructure measurements. The former was performed in a PANalytical materials research diffraction (MRD) system. The orientation distribution functions (ODFs) were obtained using the inversion of four incomplete X-ray pole figures and MTM-FHM software. ${ }^{[63]}$ FHM stands for "fast harmonic method" and uses standard series expansion ${ }^{[64]}$ for analysis. The representative texture of the undeformed sample was discretized ${ }^{[65]}$ into 1200 individual orientations. These orientations then were used for deformation texture simulations ${ }^{[63]}$ using appropriate (Table II) strain tensors. The simulations involved FCT as well as relaxed constrain lath (RCL) and pancake (RCP) models. The advanced LAMEL (ALAMEL) model and CPFEM also were used to predict the deformation texture evolution. Although a more detailed description of the ALAMEL model can be found in References 7 and 10, the main philosophy of the model consists of the following:

(a) Defining an infinitesimally thin cluster consisting of a planar grain boundary segment (GBS) and the adjacent grain boundary zones

Table II. Strain Tensors for the Selected, as in Fig. 1 and Table I, Samples

\begin{tabular}{lccc}
\hline Strain Path & LS & \multicolumn{3}{c}{ HS } \\
\hline US & {$\left[\begin{array}{ccc}0.11 & 0.00 & 0.00 \\
0.00 & -0.05 & 0.00 \\
0.00 & 0.00 & -0.06\end{array}\right]\left[\begin{array}{ccc}0.33 & 0.00 & 0.00 \\
0.00 & -0.14 & 0.00 \\
0.00 & 0.00 & -0.19\end{array}\right]$} \\
PS & {$\left[\begin{array}{ccc}0.09 & 0.00 & 0.00 \\
0.00 & 0.01 & 0.00 \\
0.00 & 0.00 & -0.10\end{array}\right]$} & {$\left[\begin{array}{ccc}0.31 & 0.00 & 0.00 \\
0.00 & 0.03 & 0.00 \\
0.00 & 0.00 & -0.34\end{array}\right]$} \\
BS & {$\left[\begin{array}{ccc}0.10 & 0.00 & 0.00 \\
0.00 & 0.08 & 0.00 \\
0.00 & 0.00 & -0.18\end{array}\right] \quad\left[\begin{array}{ccc}0.34 & 0.00 & 0.00 \\
0.00 & 0.14 & 0.00 \\
0.00 & 0.00 & -0.48\end{array}\right]$} \\
\hline
\end{tabular}

Table I. Selected Samples, for the Present Study, from the Experimental FLC (Fig. 1). Major, Minor and Von Mises Effective ${ }^{[58]}$ Strains are Listed

\begin{tabular}{|c|c|c|c|c|c|c|c|c|c|}
\hline & \multicolumn{3}{|c|}{ US } & \multicolumn{3}{|c|}{ PS } & \multicolumn{3}{|c|}{ BS } \\
\hline & $\begin{array}{c}\text { Major } \\
\text { Strain }\left(\varepsilon_{1}\right)\end{array}$ & $\begin{array}{c}\text { Minor } \\
\text { Strain }\left(\varepsilon_{2}\right)\end{array}$ & $\begin{array}{l}\text { Effective } \\
\text { Strain }(\bar{\varepsilon})\end{array}$ & $\begin{array}{c}\text { Major } \\
\text { Strain }\left(\varepsilon_{1}\right)\end{array}$ & $\begin{array}{c}\text { Minor } \\
\text { Strain }\left(\varepsilon_{2}\right)\end{array}$ & $\begin{array}{l}\text { Effective } \\
\text { Strain }(\bar{\varepsilon})\end{array}$ & $\begin{array}{c}\text { Major } \\
\text { Strain }\left(\varepsilon_{1}\right)\end{array}$ & $\begin{array}{c}\text { Minor } \\
\text { Strain }\left(\varepsilon_{2}\right)\end{array}$ & $\begin{array}{l}\text { Effective } \\
\text { Strain }(\bar{\varepsilon})\end{array}$ \\
\hline LS & 0.11 & -0.05 & 0.11 & 0.09 & 0.01 & 0.11 & 0.1 & 0.08 & 0.18 \\
\hline HS & 0.33 & -0.14 & 0.33 & 0.31 & 0.03 & 0.41 & 0.34 & 0.14 & 0.48 \\
\hline
\end{tabular}


(b) Ensuring that the cluster achieves the macroscopic applied strain while the constituting grains undergo heterogeneous strain. The later satisfies relaxed kinematical constraints and minimizes the deformation energy of the cluster

(c) After each strain increment, the new deformation texture is assumed to be a weighted average of the textures in the thin zones at both sides of the GBS. Each of the zones is assigned a weighting factor approximated to the grain segment (extending from GBS halfway into the grain)

Crystal plasticity finite element simulations were performed using an elastic-viscoplastic constitutive law adapted to crystals deformed by dislocation slip implemented in ABAQUS as user-defined material subroutine, the details of which can found in Delannay et al.$^{[11]}$ Ambiguity associated with slip system activity was avoided using the following viscoplastic expression for the slip rates:

$$
\dot{\gamma}^{\alpha}=\dot{\gamma}_{0}\left|\frac{\tau^{\alpha}}{\tau_{c}}\right|^{1 / m} \operatorname{sign}\left(\tau^{\alpha}\right)
$$

where $\dot{\gamma}^{\alpha}$ is the slip rate on slip system $\alpha, \dot{\gamma}_{0}$ is a reference slip rate, and $m$ is an exponent of the same order of magnitude as the material rate sensitivity. $\tau^{\alpha}$ is the resolved shear stress on slip system $\alpha$. The critical resolved shear stress $\tau^{c}$ is assumed to be equal on all slip systems. A Swift Law is as follows used to model hardening:

$$
\tau_{c}=\tau_{c_{0}}\left(1+\frac{\Gamma_{\text {tot }}}{\Gamma_{0}}\right)^{n}
$$

where

$$
\Gamma_{\text {tot }}=\int_{0}^{t} \sum_{\alpha}\left|\dot{\gamma}^{\alpha}\right| d t
$$

The material parameters used for the current study are given in Table III. Slip was assumed to occur

Table III. Material Parameters used in the CPFEM Simulations

\begin{tabular}{lccccccc}
\hline$\dot{\gamma}_{0}$ & $\mathrm{~m}$ & $\tau_{\mathrm{co}}$ & $\mathrm{n}$ & $\mathrm{C}_{11}$ & $\mathrm{C}_{12}$ & $\mathrm{C}_{44}$ & $\Gamma_{0}$ \\
\hline $0.001 \mathrm{sec}^{-1}$ & 0.012 & $15.0 \mathrm{MPa}$ & 0.285 & $98.0 \mathrm{GPa}$ & $60.0 \mathrm{GPa}$ & $29.0 \mathrm{GPa}$ & 0.0005 \\
\hline
\end{tabular}

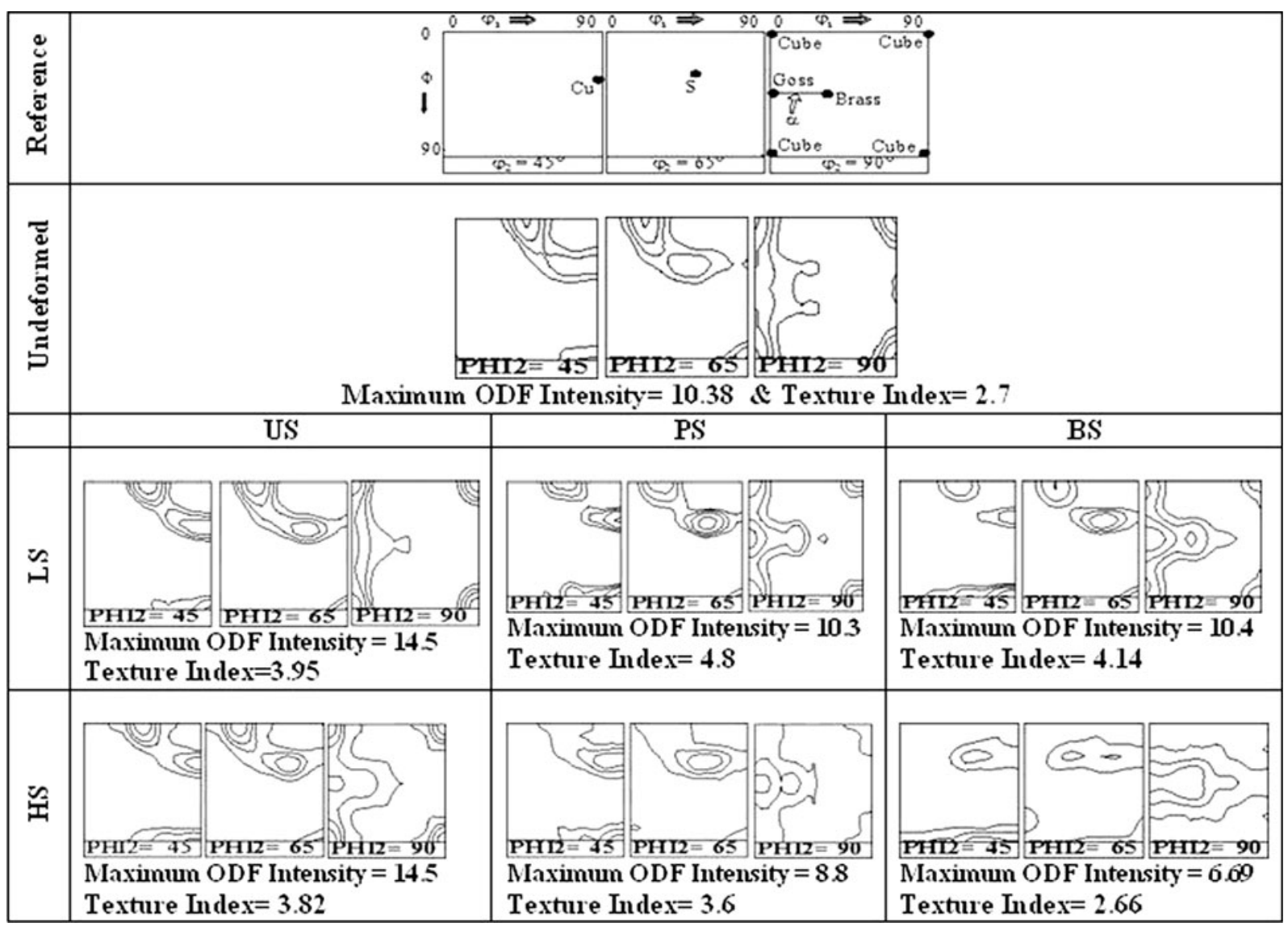

Fig. $2-\Phi_{2}=45 \mathrm{deg}, 65 \mathrm{deg}$, and $90 \mathrm{deg}$ sections of X-ray ODFs. Prior deformation ODF and reference sections of fcc ideal orientations are included. Contour levels are at 1.5, 3, 5, 9, and 16 times random. Also given are the maximum ODF intensity and texture index values. 
according to $12\{111\}\langle 110\rangle$ systems. The initial microstructure was represented by 1200 grains with each grain consisting of eight first order elements (thus allowing for intragranular heterogeneity as well) with a total of 9600 elements in the calculations.

Experimentally measured textures were compared with those obtained from simulations.**

** Only the HS (see Tables I and II) was used.

The following rationales were used for such comparisons: relative deviation parameter (RDP) ${ }^{[66]}$ and texture difference indices $\operatorname{ID}_{\mathrm{N}}{ }^{[10]}$ For the former, volume fractions were estimated for cube $\{001\}\langle 100\rangle$, copper $(\mathrm{Cu})\{112\}\langle 111\rangle, \mathrm{S}\{123\}\langle 634\rangle$, and brass $\{110\}\langle 112\rangle$ texture components. ${ }^{[67]}$ The RDP then was estimated ${ }^{[66]}$ as follows:

$$
\mathrm{RDP}=\left[\Sigma_{i}\left(\Delta c_{i} / V_{c}\right)^{2}\right]^{1 / 2}
$$

where $\Delta c_{i}$ is the difference between the experimental and the simulated volume fractions of ideal orientation $i$ and $V_{c}$ represents the experimental volume fraction. The quantitative comparison of textures was extended as follows through an integration of the difference of the orientation distribution functions in Euler space ${ }^{[10]}$ :

$$
\text { Texture Difference Indices } \operatorname{ID}_{\mathrm{N}}=\frac{\int\left(f_{1}(g)-f_{2}(g)\right)^{2} d g}{\int\left(f_{1}(g)^{2}\right) d g}
$$

where $f_{1}(g)$ and $f_{2}(g)$ are the ODF values for the experimental and simulated textures, respectively. It should be noted that texture indices $\left(\int f(g)^{2} d g\right)$ are taken as an indicator of relative anisotropy or texturing. ${ }^{[10,11]}$ It is a better representation of texturing than the more traditional maximum ODF intensity $\left(f(\mathrm{~g})_{\text {Maximum }}\right)$ values.

For electron back-scattered diffraction (EBSD) measurements a FEI Quanta 3d field emission gun (FEG) scanning electron microscope (SEM) with TexSEM Laboratories, EBSD, or orientation imaging microscopy system was used. For each sample, an area of $1 \mathrm{~mm}^{2}$ was scanned with a step size $0.2 \mu \mathrm{m}$. Grains were identified from the presence of a continuous boundary with misorientations larger than $5 \mathrm{deg}$. The present study used this criterion to estimate in-grain misorientation as well as to demarcate near boundary gradient zones (NBGZ). ${ }^{[45,46]}$ A computer program was written to identify such zones automatically from the EBSD scans.

\section{RESULTS}

The initial texture of the material as shown in Figure 2 consists of the $\mathrm{S}$, goss, and cube texture components. After deformation, different strain modes resulted in different textures, more so at higher strain. Subsequent analyses and simulations hence were restricted only to the high strains. Although plane strain and uniaxial tension resulted in similar final textures, biaxial tension resulted in a different texture, most noticeable in that is the substantial presence of the brass texture component (Figure 3). The textures obtained after biaxial tension are in agreement with earlier published results. Zhou and Neale ${ }^{[68]}$ studied both the influence of the initial texture and the ratio of the major to the minor strain in the biaxial stretching of Al alloys. They predict that, for biaxial stretching wherein the ratio of $d_{22} / d_{11}$ is smaller than 0.5 (in the current case, the value of $d_{22} / d_{11}$ is 0.412 ), the intensity of the alpha fiber increases quickly at the cost of the beta fiber intensity. The macroscopic texture confirms this finding (Figure 3). It implies that the grains with lattice orientation initially in the beta fiber have flowed quickly into the alpha fiber region in the Euler space.

As described earlier (Section II), deformation texture simulations were carried out with several models. The results of such simulations are collated in Figure 4, as appropriate ODF sections, and in Figure 5, as textureestimated volume fractions of the ideal face-centered

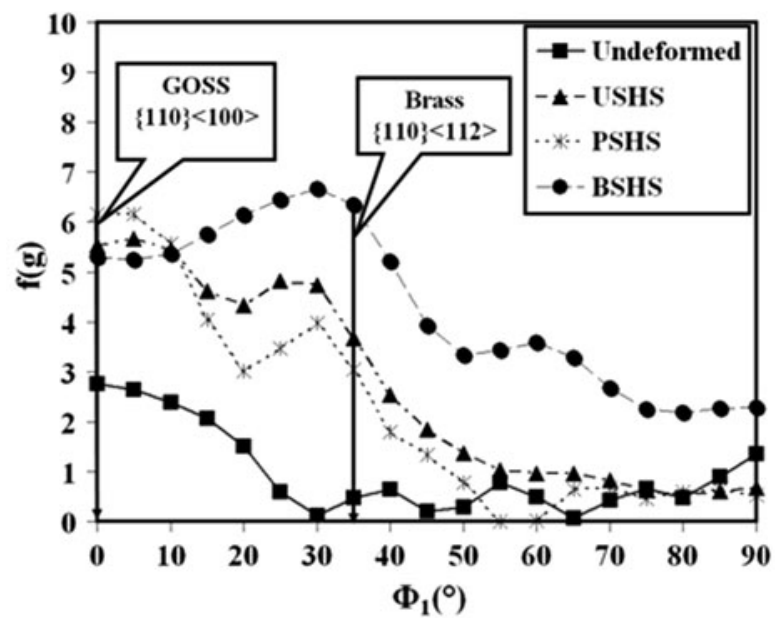

(a)

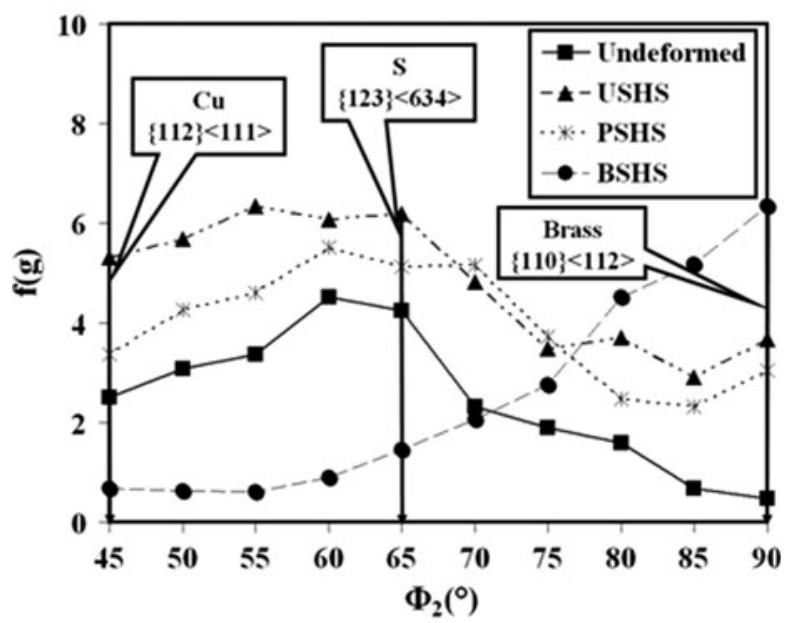

(b)

Fig. 3-Fiber intensities along ideal ${ }^{[67]}(a) \propto$ (ND parallel to $\left.\langle 110\rangle\right)$ and $(b) \beta(\langle 110\rangle$ tilted 60 deg toward the RD) fibers. The locations of $\mathrm{Cu}\{112\}\langle 111\rangle, \mathrm{S}\{123\}\langle 634\rangle$, Brass $\{110\}\langle 112\rangle$ and Goss $\{110\}$ $\langle 100\rangle$ are marked. 
cubic (fcc) texture components. As shown in the figures, although FCT could capture the developments in US, it was significantly less successful in PS and even less so in BS. The Alamel model and the CPFEM, however, could capture deformation texture developments relatively better, irrespective of the strain mode. The effectiveness of different models also is highlighted through RDP (Table IV) and texture difference indices ID $_{\mathrm{N}}($ Table V). These values, especially for texture difference indices
$\mathrm{ID}_{\mathrm{N}}$, substantiate the earlier description on deformation texture predictions, with classical Taylor type models being successful for US, whereas the ALAMEL and the CPFEM were effective irrespective of the strain mode.

To seek an answer for such differences in texture predictability, microstructural developments, especially in terms of NBGZ, ${ }^{[45,46]}$ were investigated (Figure 6). In a recent study, ${ }^{[45]}$ the NBGZ was effectively identified using $g_{\text {avg }}$, the normalized average of the quaternions

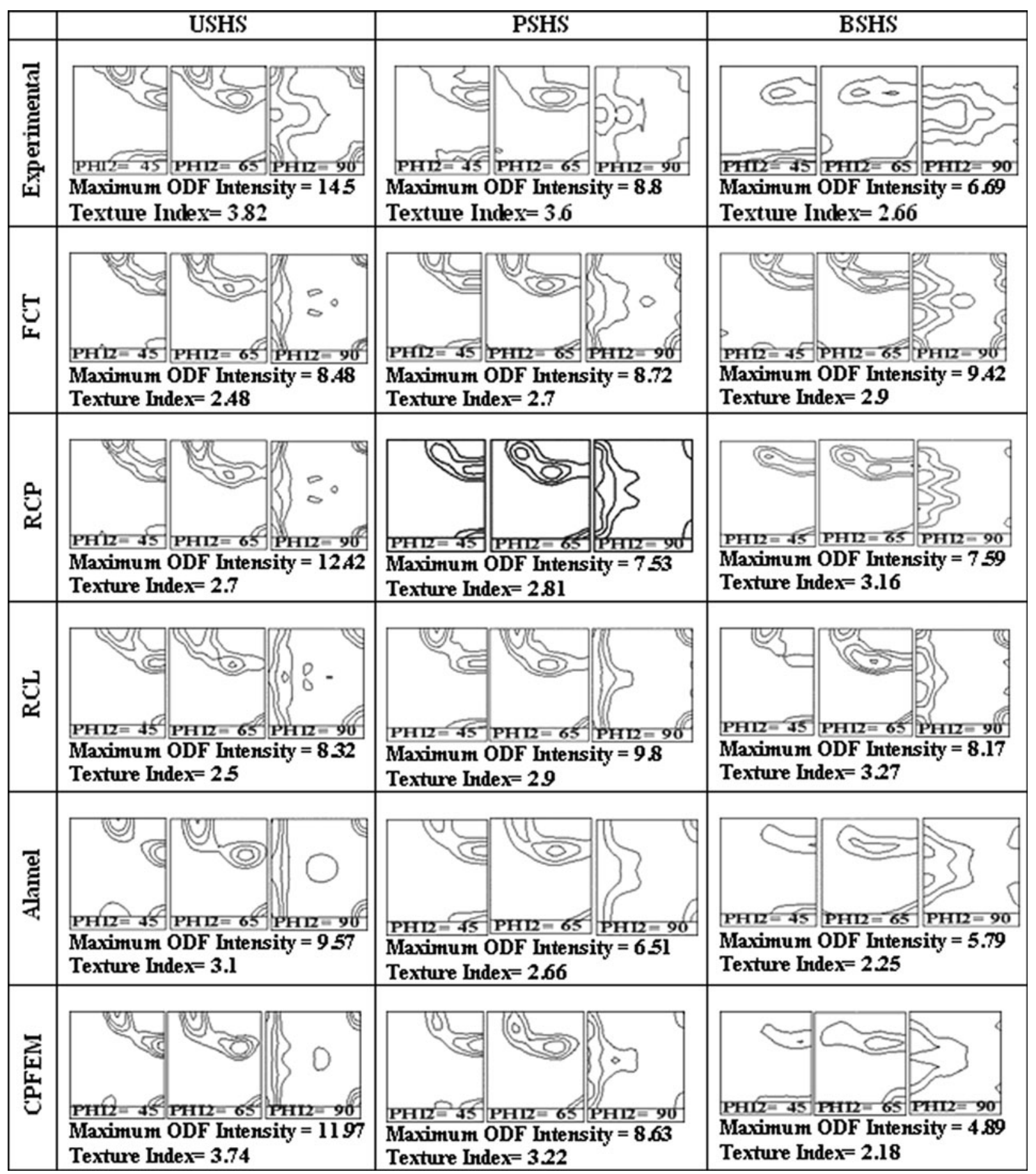

Fig. 4 -Experimental and simulated textures in $\Phi_{2}=45 \mathrm{deg}, 65 \mathrm{deg}$, and $90 \mathrm{deg}$ ODF sections. Texture simulations were conducted by FCT, RCP, RCL, Alamel, and CPFEM models. Other graphics and representations follow the same conventions as in Fig. 2. 

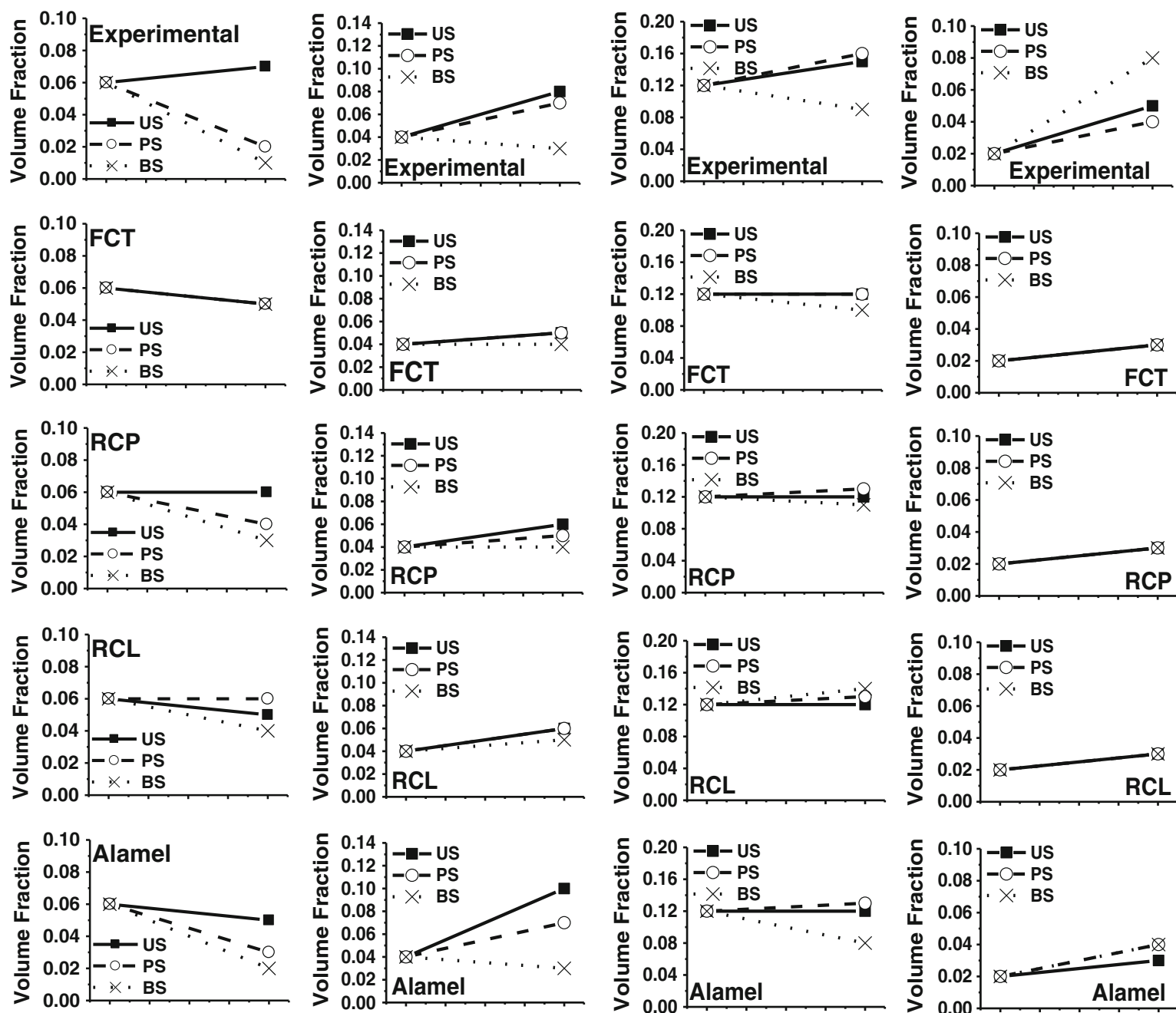

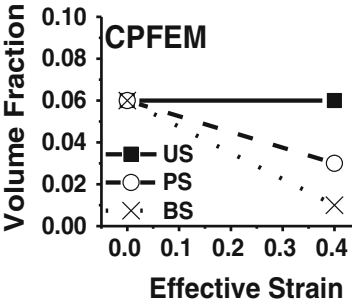

(a)

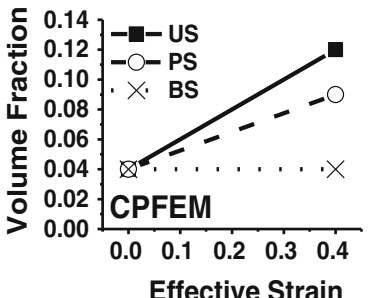

(b)

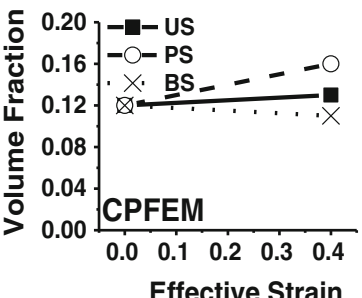

(c)

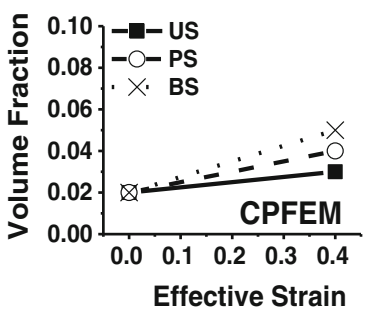

(d)

Fig. 5-Volume fractions estimated from experimental (Fig. 2) and simulated (Fig. 4) ODFs for ideal fcc texture components ${ }^{[67]}$ of $(a)$ cube $\{001\}\langle 100\rangle,(b) \mathrm{Cu}\{112\}\langle 111\rangle,(c) \mathrm{S}\{123\}\langle 634\rangle$, and (d) Brass $\{110\}\langle 112\rangle$.

Table IV. RDP: $\left[\Sigma_{i}\left(\Delta c_{i} / V_{c}\right)^{2}\right]^{1 / 2}$ Where $\Delta c_{i}$ is the Difference Between the Experimental and Simulated Volume Fractions of Ideal Orientation $i$ and $V_{c}$ Represents the Experimental Volume Fraction. RDP Values are Estimated for Cube $\{001\}\langle 100\rangle, \mathrm{Cu}$ $\{112\}\langle 111\rangle, \mathrm{S}\{123\}\langle 634\rangle$, and Brass $\{110\}\langle 112\rangle$ and Are Listed for all Three Strain Modes

\begin{tabular}{|c|c|c|c|c|c|c|c|c|c|c|c|c|}
\hline \multirow[b]{2}{*}{ Type of Model } & \multicolumn{4}{|c|}{ USHS } & \multicolumn{4}{|c|}{ PSHS } & \multicolumn{4}{|c|}{ BSHS } \\
\hline & Cube & $\mathrm{Cu}$ & $\mathrm{S}$ & Brass & Cube & $\mathrm{Cu}$ & $\mathrm{S}$ & Brass & Cube & $\mathrm{Cu}$ & $\mathrm{S}$ & Brass \\
\hline FCT & 0.28 & 0.27 & 0.19 & 0.41 & 1.53 & 0.34 & 0.26 & 0.22 & 4.16 & 0.49 & 0.18 & 0.62 \\
\hline $\mathrm{RCP}$ & 0.2 & 0.24 & 0.16 & 0.41 & 1.11 & 0.33 & 0.23 & 0.27 & 2.44 & 0.51 & 0.26 & 0.64 \\
\hline RCL & 0.26 & 0.24 & 0.17 & 0.42 & 1.73 & 0.26 & 0.18 & 0.28 & 3.71 & 0.73 & 0.64 & 0.64 \\
\hline Alamel & 0.24 & 0.37 & 0.17 & 0.37 & 0.49 & 0.12 & 0.18 & 0.15 & 1.97 & 0.22 & 0.04 & 0.48 \\
\hline CPFEM & 0.2 & 0.59 & 0.08 & 0.51 & 0.47 & 0.19 & 0.03 & 0.09 & 1.5 & 0.68 & 0.28 & 0.44 \\
\hline
\end{tabular}


describing all orientations in the grain. The misorientation spread inside a grain can be estimated as follows: $\Delta \theta_{i}=\mathbf{g}_{\mathrm{avg}} \cdot \mathrm{g}_{\mathrm{i}}^{-1}$, where $\mathbf{g}_{\mathrm{i}}$ and $\Delta \theta_{\mathrm{i}}$ are the respective values of the measured orientation and the estimated misorientation spread. Such misorientation spreads are shown graphically in Figures 6(a) and (b) as well as numerically in Figures 6(c) and (d). This brings out two important points. First, the misorientation spreads increased from US to PS to BS, with BS exhibiting

Table V. Texture Difference Indices ID $_{\mathrm{N}}=\frac{\int\left(f_{1}(g)-f_{2}(g)\right)^{2} d g}{\int\left(f_{1}(g)^{2}\right) d g}$

Where $f_{1}(g)$ and $f_{2}(g)$ are the ODF Values for the Experimental and Simulated Textures, Respectively. These Were Estimated from All Models and at All Three Strain Modes

\begin{tabular}{lccc}
\hline Simulations & USHS & PSHS & BSHS \\
\hline FCT & 0.65 & 0.66 & 1.54 \\
RCP & 0.59 & 0.61 & 1.53 \\
RCL & 0.64 & 0.87 & 1.96 \\
Alamel & 0.77 & 0.31 & 0.64 \\
CPFEM & 0.78 & 0.63 & 0.71 \\
\hline
\end{tabular}

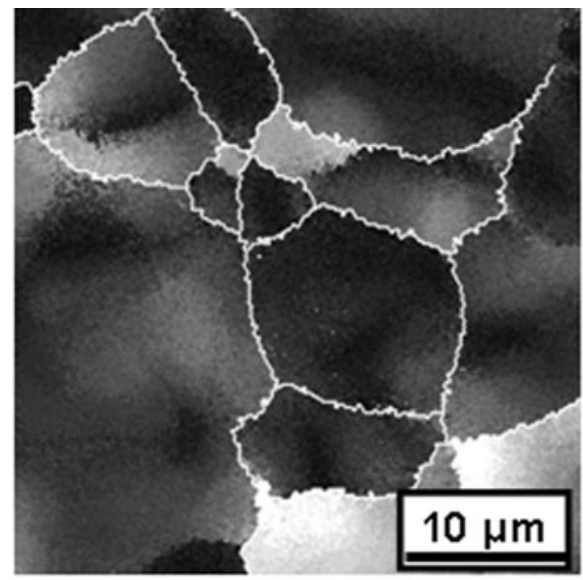

(a)

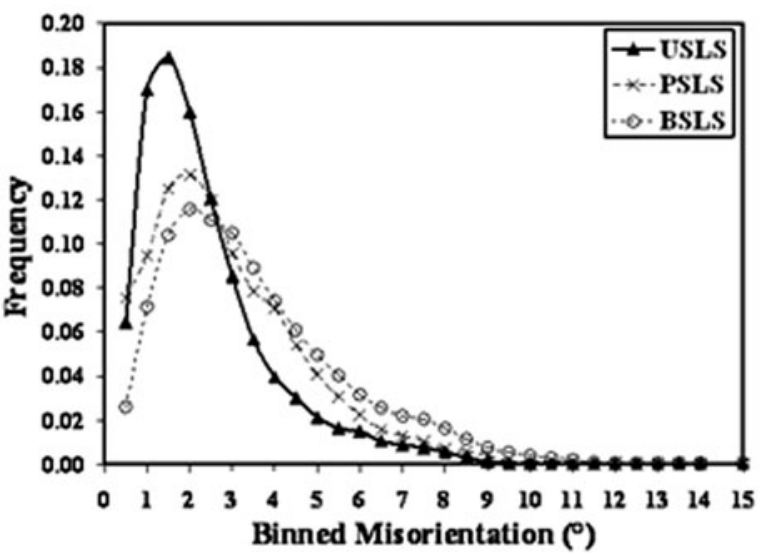

(c)

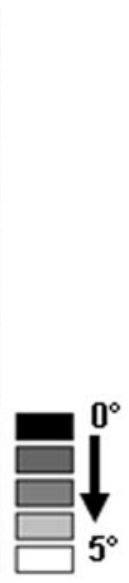

$5^{\circ}$ significantly higher spreads. Second, the misorientation spreads were often (qualitatively) near the grain boundary regions.

An algorithm (Figure 7) and a corresponding computer program were prepared. Based on a user-defined misorientation spread and the cut-off angle, the program could separate near boundary gradient zones from the EBSD data. This simple, albeit numerically intensive, procedure could bring out average line profiles (Figure 8). Figure 8 and Tables VI and VII reconfirm the earlier observation (Figures 6(c) and (d)) of an increased orientation gradient from US to PS to BS. Even more importantly, Figure 8 shows quantitatively that such orientation gradients were largely in the NBGZs. The fragmentation of grains, especially apparent at BSHS (Figure 6(b)) contributed to the overall orientation gradients, but even then, NBGZs seem to be the strongest contributor.

\section{DISCUSSION}

Direct experimental results could establish the following: (1) strain mode dependence of deformation

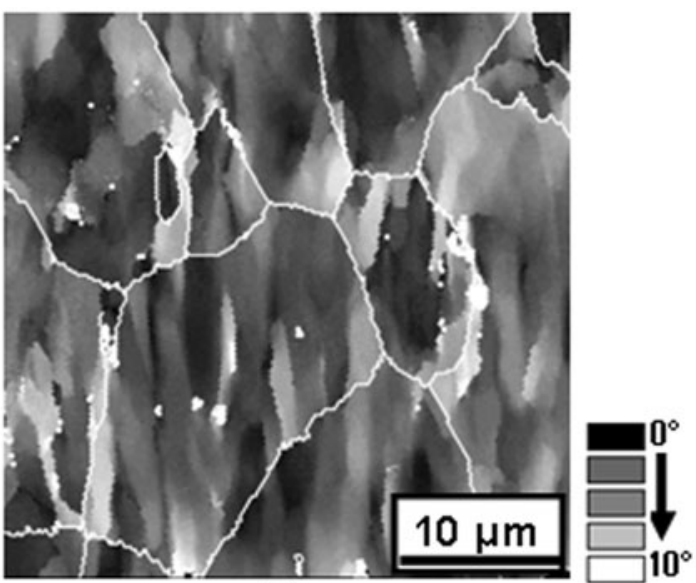

(b)

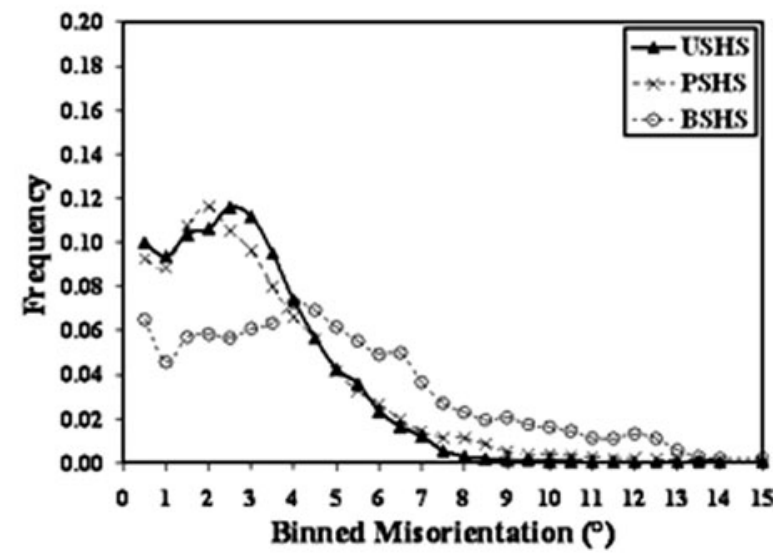

(d)

Fig. 6-EBSD maps of (a) USLS and (b) BSHS. The misorientation spreads, with respect to quaternion average of the grain orientation, ${ }^{[45]}$ were plotted in gray scale. For example, black meant zero spread, whereas white represents respective spreads of 5 deg and 10 deg. The misorientation spreads, as in $(a)$ and $(b)$, were plotted for all three strain modes and for $(c)$ LS and $(d)$ HS strains. 


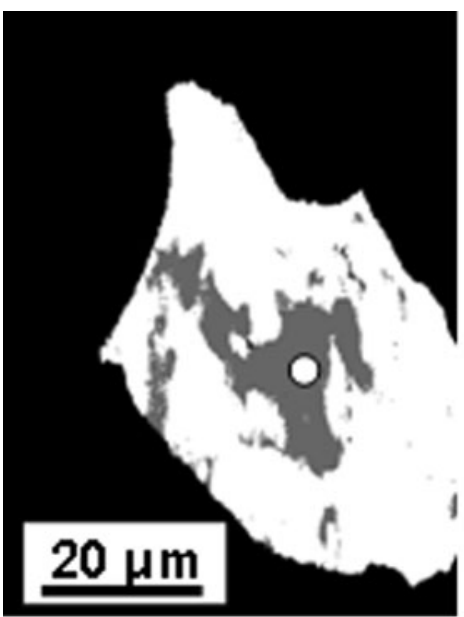

(a)

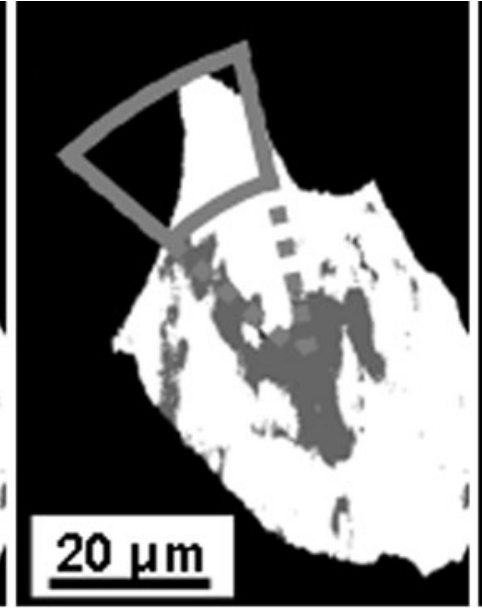

(b)

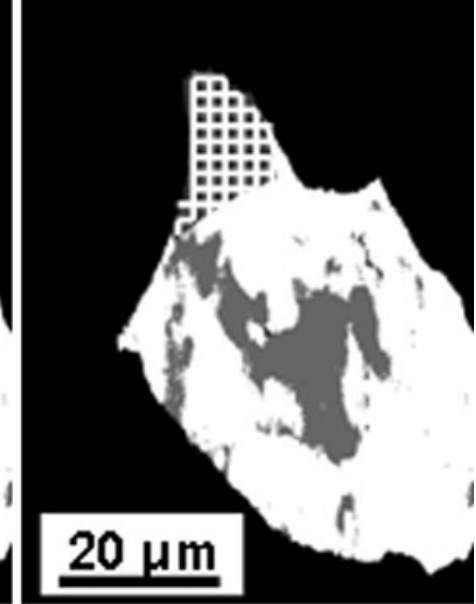

(d)

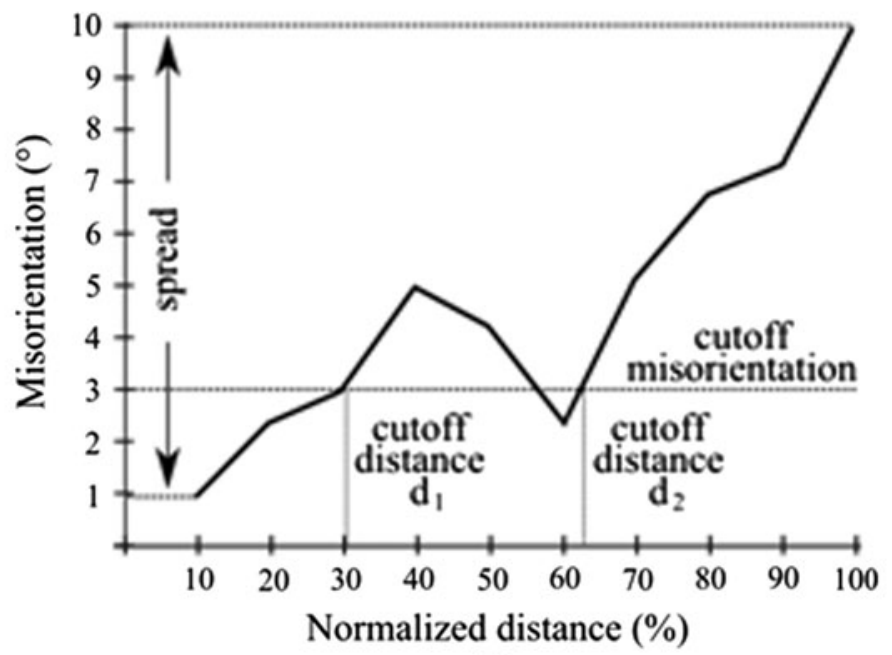

(c)

Fig. 7-The algorithm for estimating NBGZ. Grains larger than a user-defined minimum size (5 $\mu \mathrm{m}$ in the present study) were considered. (a) Geometric centers of the grains then were identified. This was done by fitting an ellipse and then identifying the center as the intersection between major and minor axes. (b) From the center, each grain then was divided into segments of 30 deg. This was done by clockwise rotations from " $+\mathrm{x}$ " direction. Such a segment was analyzed if the misorientation spread exceeded a user-specified value. Misorientation spread was estimated as the $\Delta \theta_{\text {Max }}-\Delta \theta_{\text {Min }}$, the maximum and minimum misorientation values. Misorientation or $\Delta \theta_{i}, \Delta \theta_{i}=\mathrm{g}_{\text {avg }} \cdot \mathrm{g}_{i}^{-1} \longrightarrow$ where $\mathrm{g}_{\text {avg }}$ is the normalized average quaternion of all orientations in the grain and $\mathrm{g}_{\mathrm{i}}$ represented the measured orientation(s) or EBSD data. (c) For the "qualified" segments, line profiles of misorientation $\left(\Delta \theta_{\mathrm{i}}\right) v s$ normalized distance (from center to the boundary) then were calculated. This was done from the grain center to each point on the boundary. From such line profiles, cut-off distance(s) were estimated. In "multiple cut-off distances," the one closest to the boundary (e.g., $\mathrm{d}_{2}$ ) was taken. (d) The gradient zone is a union of all neighboring points in a segment satisfying user-defined misorientation spread and cut-off angle.

textures and (2) relative inability of the "one-point" Taylor models to capture this observation. This, in itself, is not a novel observation. The present set of data is somewhat more comprehensive than previous reports about this trend. ${ }^{[58,59]}$ Novelty starts with the observation that the apparent success or failure of "one-point" models seems to correlate with the relative presence of the NBGZs (Figure 7). This point is extended in Figure 9. Texture difference indices $\mathrm{ID}_{\mathrm{N}}$, perhaps the most rigorous method of comparing experimental and simulated textures, did clearly correlate with the gradient zone area fraction for "one-point" models. For the ALAMEL and the CPFEM, however, the quality of texture predictions was not affected by the relative presence of NBGZ. This tends to indicate that ALAMEL and CPFEM were successful in capturing, in general, the NBGZ and, in particular, the patterns of strain heterogeneity.

The strain mode dependence of texture and microstructure evolution was apparent in biaxial tension. In BS, developments in the brass texture component did coincide with significant heterogeneous deformation. It is also apparent that local grain interactions played a major role in the BS, which, in turn, were reflected in the NBGZ and in the development of brass. ${ }^{[69]}$ Arguably, local rolling direction (RD)-transverse direction (TD) shears ${ }^{[6]}$ can lead to the formation of brass. Although it is difficult to measure local strains experimentally, the 
same can be extracted from full-field methods like CPFEM. As in Figure 10, distributions of the local shear strains were plotted for all three strain modes. Such distributions were symmetric around a mean value of zero. This outcome is expected because all applied strain modes are of orthorhombic symmetry with no offdiagonal terms. It is, however, important to note that BS showed a relatively larger spread for all shears - more so for the RD-TD shear-hence justifying the generation of brass texture component in BS.

A natural extension of the present analysis is to divide the microtexture data into NBGZ and non-NBGZ textures and then to compare them with deformation texture simulations. This raises the following problems:

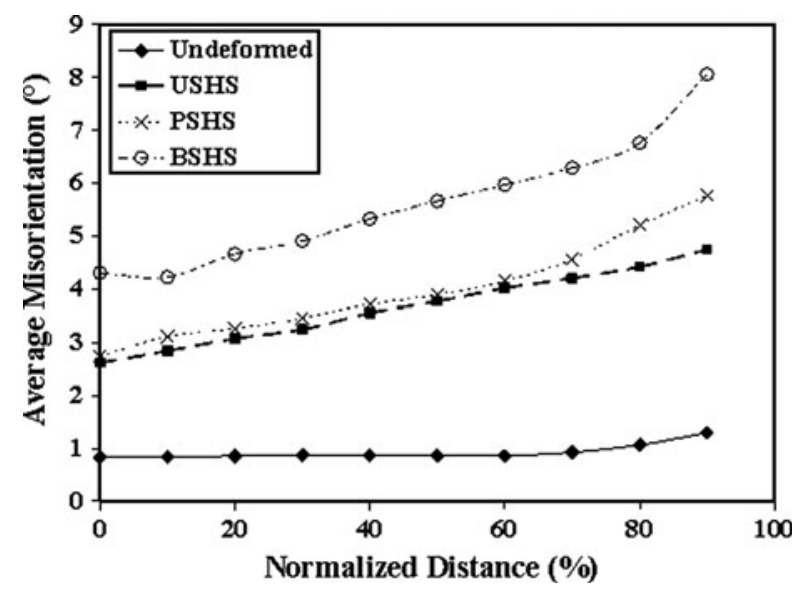

Fig. 8-Average misorientation profiles, as in Fig. 7(c), for different strain modes. The data represent average $\Delta \theta_{\mathrm{i}} v s$ normalized distance from the grain center. These were estimated from the EBSD data of the respective grains: $\Delta \theta_{i}=\mathbf{g}_{\text {avg }} \cdot \mathbf{g}_{i}^{-1}$-where $\mathrm{g}_{\text {avg }}$ is the normalized average quaternion of all orientations in the grain and $\mathrm{g}_{\mathrm{i}}$ represented the measured orientation(s) or EBSD data. the characteristic "limited" nature of the EBSD data and the fact that divisions between NBGZ and nonNBGZ textures are, at best, ad-hoc. The first, and the most critical, problem is not only through limited statistics but also from the inability of EBSD, even in a FEG SEM, to index regions of extreme strain concentrations and large lattice curvatures. This, however, makes the microtexture data, especially the high strain data, quantitatively different from the corresponding bulk texture measurements. Even though a definitive comparison between characteristic NBGZ/ non-NBGZ textures and deformation texture simulations is not practical, a semiquantitative evaluation could provide the following generalized trends: (1) the "one-point" models were reasonably successful and deficient at capturing respective non-NBGZ and NBGZ textures. (2) Alamel and CPFEM, however, had nearly the same success in bringing out the textures of both types of regions.

Another interesting point is made (Figure 11) on relative lattice reorientations or rotations. Although Figure 11 is specific to the cube orientation/stability, similar observations were made for other unstable orientations as well. As in Figure 11, and estimated through the so-called high-resolution ODFs, ${ }^{[62]}$ signatures of lattice reorientations or rotations were remarkably similar between the strain modes. For example, the initial or undeformed cube was mostly normal direction (ND) rotated. Deformation reoriented the cube to TDRD rotations. ${ }^{[40,62]}$ Such reorientations were qualitatively similar, although the exact magnitude did differ between the strain modes.

This observation (Figure 11), coupled with observations of "one-point" models (Figures 4 and 5), has interesting connotations. "One-point" models, especially FCT, did predict similar textures (Figure 4) and nearly identical changes in ideal fcc texture components

Table VI. Average Values of Minimum, Maximum and Misorientation Spreads Were Estimated from Line Profiles, as in Figs. 7(c) and 8, for the Respective Samples. Misorientation or $\Delta \theta_{i}=\mathbf{g}_{\mathrm{avg}} \cdot \mathrm{g}_{i}^{-1}$ where $\mathbf{g}_{\mathrm{avg}}$ is the Normalized Average Quaternion of All Orientations in the Grain and $g_{i}$ Represented the Measured Orientation(s) or EBSD Data

\begin{tabular}{lccc}
\hline Type of Sample & $\begin{array}{c}\text { Minimum Misorientation } \\
\text { (average): } \Delta \theta_{\text {Min }}\end{array}$ & $\begin{array}{c}\text { Maximum Misorientation } \\
\text { (average): } \Delta \theta_{\text {Max }}\end{array}$ & $\begin{array}{c}\text { Misorientation Spread } \\
\text { (average): } \Delta \theta_{\text {Max }}-\Delta \theta_{\text {Min }}\end{array}$ \\
\hline Undeformed & 0.84 & 1.29 & 0.45 \\
USHS & 2.62 & 4.74 & 2.12 \\
PSHS & 2.75 & 5.76 & 3.01 \\
BSHS & 4.3 & 8.06 & 3.76 \\
\hline
\end{tabular}

Table VII. Area Fractions of NBGZ for Different User-Defined Misorientation Spreads and Cut-Off Values. The Method for Estimating NBGZ is Shown Schematically in Fig. 7. With Various Spreads and Cut-Offs, NBGZ Estimates Differed Numerically. The Overall Trend, However, Remained the Same: NBGZ Area Fractions Increased from US to PS to BS

\begin{tabular}{lccccccccccccc}
\hline & \multicolumn{10}{c}{ User Defined Misorientation Spread and Cutoff Values } \\
\cline { 2 - 13 } Condition & $0.5 \& 1.5$ & $0.5 \& 2$ & $0.5 \& 2.5$ & $0.5 \& 3$ & $0.5 \& 4$ & $1 \& 1.5$ & $1 \& 2$ & $1 \& 2.5$ & $1 \& 3$ & $1 \& 4$ & $2 \& 2.5$ & $2 \& 3$ & $2 \& 4$ \\
\hline Undeformed & 4.7 & 4.2 & 3.13 & 2.66 & 1.086 & 3.66 & 3.23 & 2.26 & 1.95 & 1.01 & 1.83 & 1.54 & 0.74 \\
USHS & 15.8 & 14.7 & 13.3 & 11.6 & 8.4 & 15.7 & 14.6 & 13.1 & 11.4 & 8.3 & 12.3 & 11 & 8 \\
PSHS & 16.6 & 16 & 14.4 & 13.4 & 10.2 & 15.5 & 15.2 & 14.4 & 13.4 & 10.1 & 13.9 & 12.3 & 8.9 \\
BSHS & 17.2 & 17.2 & 16.8 & 16.5 & 14.4 & 17.1 & 17.1 & 16.8 & 16.4 & 14.4 & 16.1 & 15.8 & 13.9 \\
\hline
\end{tabular}


(Figure 5) for all three strain modes. This drawback can be related, as discussed earlier, to the relative presence of NBGZ. Lattice reorientations/rotations in NBGZs, although qualitatively similar with the remainder of the grains, were more severe in magnitude. The presence

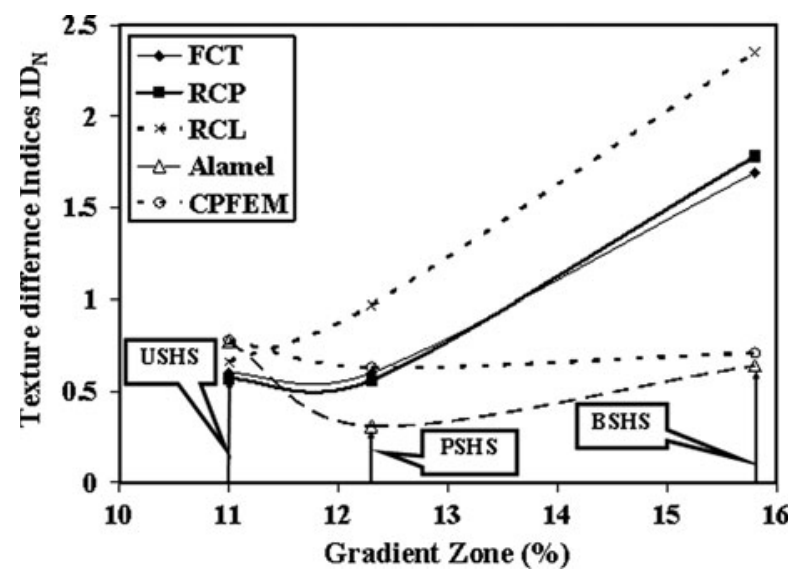

Fig. 9-Texture difference indices $\mathrm{ID}_{\mathrm{N}}$, Eq. [5], vs estimated gradient zone percentage. The latter was estimated by taking the user-defined spread and cut-off values as $2 \mathrm{deg}$ and $3 \mathrm{deg}$, respectively.

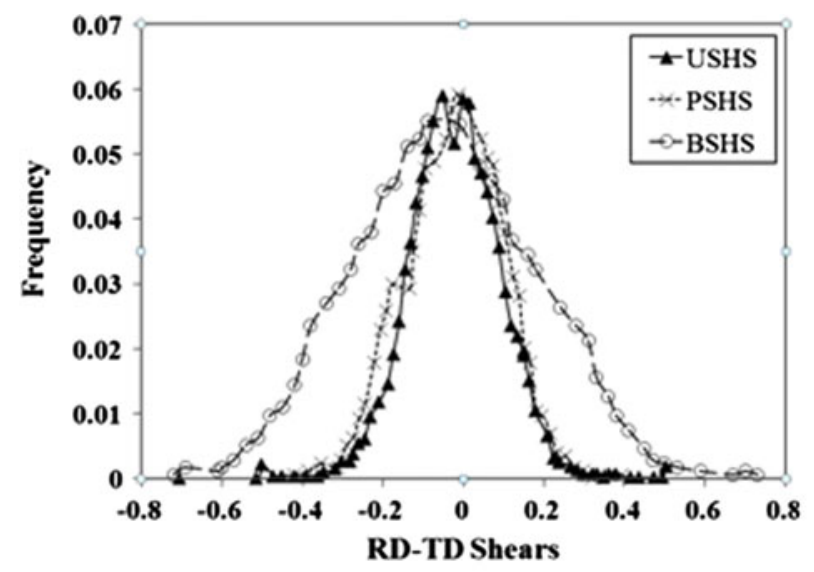

(a)

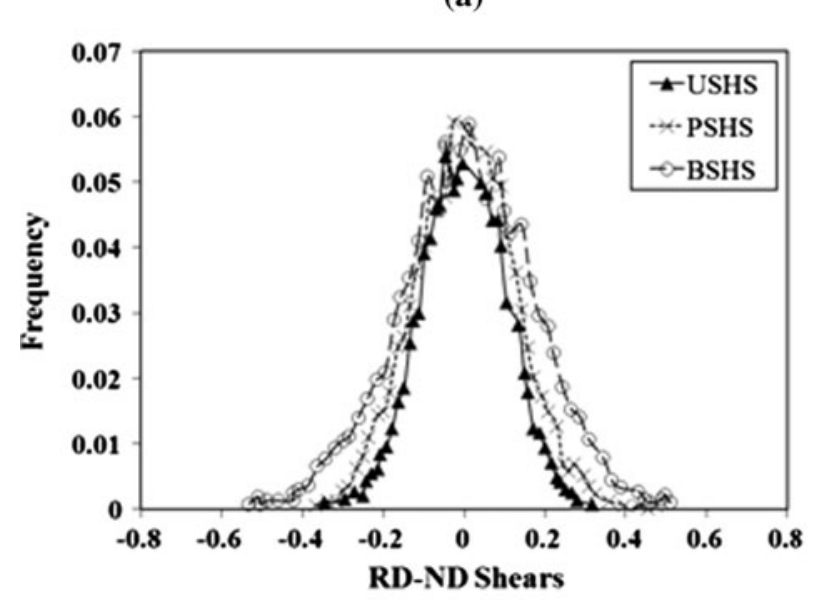

(c) of NBGZ thus reduced the maximum ODF intensity as well as the relative texturing or texture index. This, however, can explain the well-known tendency of classical FCT to predict stronger than actual deformation textures.

\section{CONCLUSIONS}

The following conclusions were made based on the results of the current study:

1. Deformation texture developments were strain mode dependent, especially at the higher strain level. From US to PS to BS, differences in deformation textures can be generalized as a drop in cube and an increase in brass component.

2. "One-point" Taylor-type models predicted similar textures and nearly identical changes in ideal fcc texture components for all three strain modes. However, the Alamel and the CPFEM were effective in bringing out strain mode effects on the deformation texture.

3. Detailed microstructural investigations reveal stronger in-grain orientation gradients from US to PS to BS. Such gradients often were found near grain

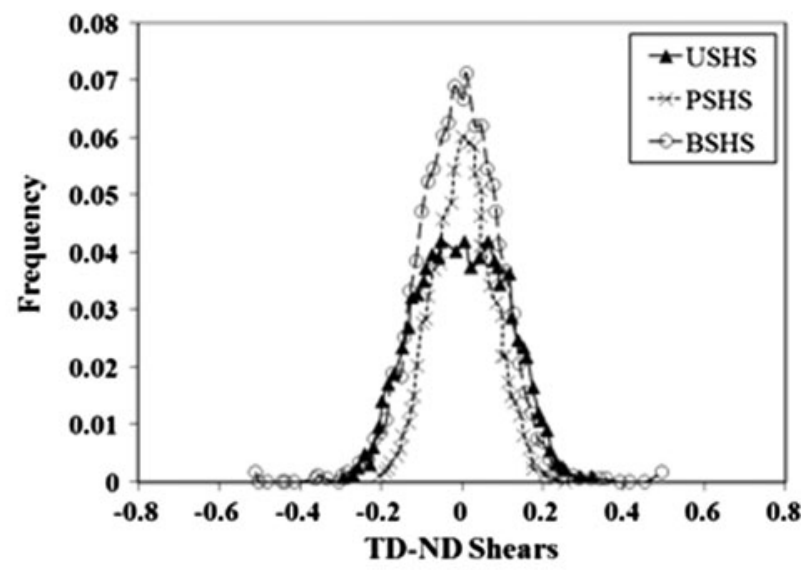

(b)

- 


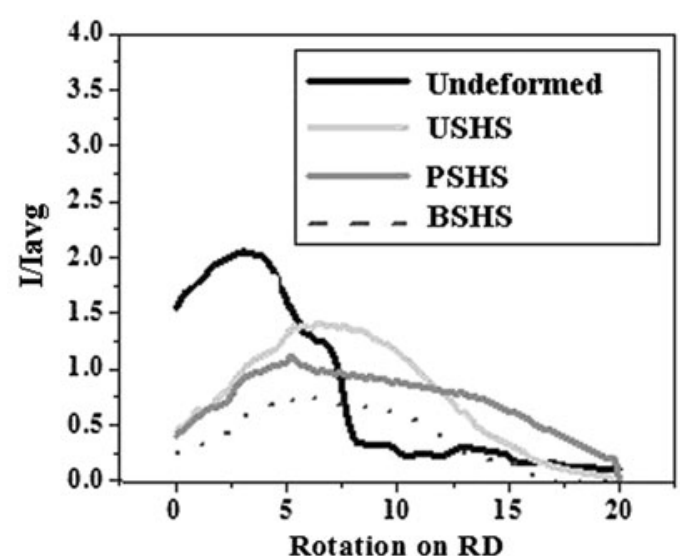

(a)

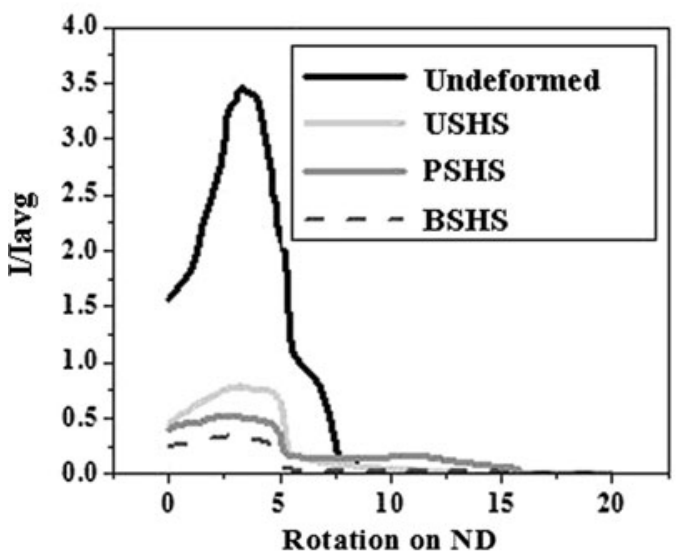

(c)

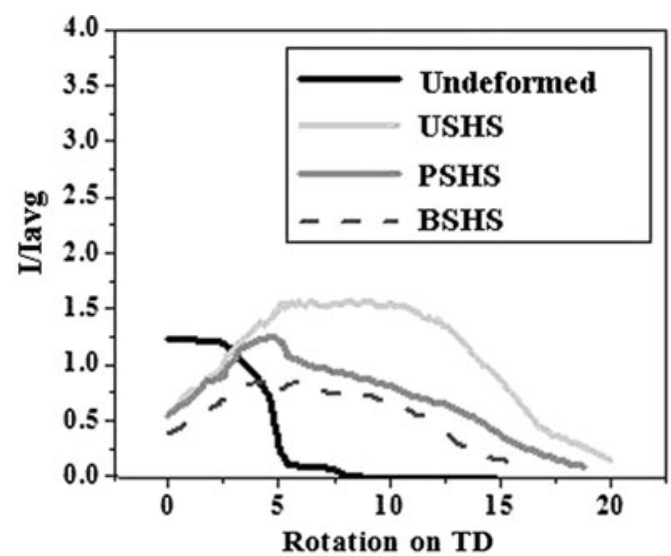

(b)

Fig. 11-Preference/rotation of Cube $\{001\}\langle 100\rangle$ with respect to $(a)$ rolling, $(b)$ transverse, and $(c)$ normal direction. These were estimated from the EBSD data and high-resolution ODFs, $0.2 \mathrm{deg}$ resolution, and a methodology described elsewhere. ${ }^{[62]}$

boundary regions, generalized, through a computer algorithm as NBGZ.

4. The apparent success or failure of deformation texture simulations did depend on the relative presence of NBGZ. At low NBGZ (e.g., US), all models performed well, whereas at higher NBGZ (e.g., PS and BS), Alamel and CPFEM were more successful than the "one-point" Taylor type models.

5. Relative lattice reorientations or rotations, estimated through high-resolution ODFs, for unstable orientations (e.g., cube) were qualitatively similar between the strain modes. However, the magnitude of such rotations did depend on the strain mode as well as the relative presence of NBGZ. A stronger presence of NBGZ reduced the relative texturing and maximum ODF intensity and thus may explain the well-known tendency of classical FCT to predict stronger than actual deformation textures.

\section{ACKNOWLEDGMENTS}

The authors (S. Raveendra, S. Mishra and I. Samajdar) would like to acknowledge financial support from IFCPAR/CEFIPRA (Indo-French Centre for the Promotion of Advance Research). Texture/microtexture measurements at the National Facility of Texture \& OIM (a DST-IRPHA facility) at IIT Bombay also are acknowledged. LD is mandated by Belgium's National Fund for Scientific Research (FSR-FNRS). Funding from Belgian Science Policy through Grant IAP- 06/24 is also gratefully acknowledged.

\section{REFERENCES}

1. G.I. Taylor: J. Inst. Met., 1938, vol. 62, pp. 307-24

2. D. Raabe: Mater. Sci. Eng. A, 1995, vol. 197A, pp. 31-37.

3. W. Robert, D. Piot, and J.H. Driver: Scripta Mater., 2004, vol. 50, pp. 1215-19.

4. O. Engler, M. Crumbach, and S. Li: Acta Mater., 2005, vol. 53, pp. $2241-57$

5. P. Van Houtte, A.K. Kanjarla, A. Van Bael, M. Seefeldt, and L. Delannay: Eur. J. Mech. Solids, 2006, vol. 25, pp. 634-48.

6. T. Leffers and R.K. Ray: Progr. Mater. Sci., 2009, vol. 54, pp. $351-96$.

7. A.K. Kanjarla, P. Van Houtte, and L. Delannay: Int. J. Plast., 2010, vol. 26, pp. $1220-33$

8. L. Delannay, S.R. Kalidindi, and P. Van Houtte: Mater. Sci. Eng. A, 2002, vol. 336A, pp. 233-44.

9. G.C. Butler and D.L. Mc Dowell: Int. J. Plast., 1998, vol. 14, pp. 703-17.

10. P. Van Houtte, S. Li, M. Seefeldt, and L. Delannay: Int. J. Plast., 2005, vol. 21, pp. 589-624.

11. L. Delannay, P.J. Jacques, and S.R. Kalidindi: Int. J. Plast., 2006, vol. 22, pp. 1879-98. 
12. J.W. Yoon, F. Barlat, J.J. Gracio, and E. Rauch: Int. J. Plast., 2005, vol. 21, pp. 2426-47.

13. D.P. Mika and P.R. Dawson: Mater. Sci. Eng. A., 1998, vol. 257A, pp. 62-76.

14. F. Barbe, S. Forest, and G. Callietaud: Int. J. Plast., 2001, vol. 17, pp. $537-63$.

15. O. Diard, S. Leclercq, G. Rousselier, and G. Cailletaud: Int. J. Plast., 2005, vol. 21, pp. 691-722.

16. F. Delaire, J.L. Raphanel, and C. Rey: Acta Mater., 2000, vol. 48, pp. 1075-87.

17. U. Lienert, T.S. Han, J. Almer, P.R. Dawson, T. Leffers, L. Margulies, S.F. Nielsen, H.F. Poulsen, and S. Schmidt: Acta Mater., 2004, vol. 52, pp. 4461-67.

18. A. Musienko, A. Tatschl, K. Schmidegg, O. Kolednik, R. Pippan, and G. Cailletaud: Acta Mater., 2007, vol. 55, pp. 4121-36.

19. D. Raabe, M. Sachtleber, Z. Zhao, and S. Zaefferer: Acta Mater., 2001, vol. 49, pp. 3433-41.

20. R.A. Lebensohn, R. Brenner, O. Castelnau, and A.D. Rollett: Acta Mater., 2008, vol. 56, pp. 3914-26.

21. D. Raabe, Z. Zhao, and W. Mao: Acta Mater., 2002, vol. 50, pp. 4379-94.

22. A. Molinari, G.R. Canova, and S. Ahzi: Acta Metall., 1987, vol. 35 , pp. 2983-94.

23. R.A. Lebensohn and C.N. Tomé: Acta Metall. Mater., 1993, vol. 41, pp. 2611-24.

24. C.A. Bronkhorst, S.R. Kalidindi, and L. Anand: Phil. Trans. R. Soc. Lond., 1992, vol. A341, pp. 443-77.

25. B. Verlinden, J. Driver, I. Samajdar, and R.D. Doherty: ThermoMechanical Processing of Metallic Materials, Pergamon Materials Series, R.W. Cahn, ed., Elsevier, Amsterdam, The Netherlands, 2007.

26. B. Bay, N. Hansen, D. Hughes, and D. Kuhlmann-Wilsdorf: Acta Metall. Mater., 1992, vol. 40, pp. 205-19.

27. J.A. Wert, X. Huang, G. Winther, W. Pantleon, and H.F. Poulsen: Mater. Today, 2007, vol. 9, pp. 24-32.

28. A.K. Kanjarla, L. Delannay, and P. Van Houtte: 2010, Metall. Mater. Trans. A, in press.

29. N. Hansen and D.J. Jensen: Phil. Trans. R. Soc. Lond. A, 1999, vol. 357 , pp. $1447-69$.

30. J. Gil Sevillano, P. Van Houtte, and E. Aernoudt: Progr. Mater. Sci., vol. 25, pp. 69-412.

31. D. Kuhlmann-Wilsdorf and N. Hansen: Scripta Metall. Mater., 1991, vol. 25, pp. 1557-62.

32. Q. Liu, D.J. Jensen, and N. Hansen: Acta Mater., 1998, vol. 46, pp. $5819-38$.

33. D.K.- Wilsdorf: Phil. Mag., 1999, vol. 79A, pp. 955-1008.

34. B. Bay, N. Hansen, and D.K.- Wilsdorf: Mater. Sci. Eng. A, 1989, vol. 113A, pp. 385-97.

35. N. Hansen: Mater. Sci. Technol., 1990, vol. 6, pp. 1039-47.

36. D.A. Hughes and A. Godfrey: Proc. Hot deformation of Aluminum Alloys II, 1998, pp. 23-36.

37. N. Hansen: Metall. Mater. Trans. A, 2001, vol. 32A, pp. $2917-$ 35

38. X. Haung: Scripta Mater., 1998, vol. 38, pp. 1697-703.
39. G.L. Wu, A. Godfrey, W. Liu, and Q. Liu: Scripta Mater., 2001, vol. 45 , pp. $1117-22$.

40. F. Basson and J.H. Driver: Acta. Mater., 2000, vol. 48, pp. 210115.

41. S.R. Kalidindi, A. Bhattacharya, and R.D. Doherty: Proc. R. Soc. Lond., 2004, vol. 460A, pp. 1935-56.

42. I.L. Dillamore, P.L. Morris, C.J.E. Smith, and W.B. Hutchinson: Proc. R. Soc. Lond. A, 1972, vol. 329A, pp. 405-20.

43. J.A. Wert, Q. Liu, and N. Hansen: Acta Mater., 1997, vol. 45, pp. $2565-76$

44. L. Delannay, O.V. Mishin, D.J. Jensen, and P. Van Houtte: Acta Mater., 2001, vol. 49, pp. 2441-51.

45. S.K. Mishra, P. Pant, K. Narasimhan, A.D. Rollet, and I. Samajdar: Scripta Mater., 2009, vol. 61, pp. 273-76.

46. L.S. Tóth, Y. Estrin, R. Lapovok, and C. Gu: Acta Mater., 2010, vol. 58 , pp. $1782-94$.

47. G. Thorning, M.A.J. Somers, and J.A. Wert: Mater. Sci. Eng. A, 2005, vol. 397A, pp. 215-28.

48. R. Becker and S. Panchanandeswaran: Acta Metall. Mater., 1995, vol. 7, pp. 2701-19.

49. R. Becker: Acta Metall. Mater., 1991, vol. 6, pp. 1211-30.

50. H.F. Poulsen, L. Margulies, S. Schmidt, and G. Winther: Acta Mater., 2003, vol. 51, pp. 3821-30.

51. S. Van Boxel, M. Seefeldt, B. Verlinden, and P. Van Houtte: J. Microsc., 2005, vol. 218, pp. 104-14.

52. H. Paul, J.H. Driver, and W. Wajda: Mater. Sci. Eng. A, 2008, vol. 477A, pp. 282-94.

53. L. Delannay, R.E. Logé, Y. Chastel, and P. Van Houtte: $A d v$. Eng. Mater., 2003, vol. 8, pp. 597-600.

54. T. Leffers: Int. J. Plast., 2001, vol. 17, pp. 491-511.

55. M. Seefeldt, L. Delannay, B. Peeters, E. Aernoudt, and P. Van Houtte: Acta Mater., 2001, vol. 49, pp. 2129-43.

56. M. Sachtleber, Z. Zhao, and D. Raabe: Mater. Sci. Eng. A, 2002, vol. 336A, pp. 81-7.

57. L.S. Toth, P. Gilormini, and J.J. Jonas: Acta Metall., vol. 36, pp. 3077-91.

58. S.K. Mishra: Ph.D. Dissertation, IIT, Bombay, India, 2009.

59. S.K. Mishra, S.G. Desai, P. Pant, K. Narasimhan, and I. Samajdar: Int. J. Mater. Form, 2009, vol. 2, pp. 59-67.

60. S.S. Hecker: Mech. Eng. Q., 1974, vol. 14, pp. 30-36.

61. S.S. Hecker: Sheet Metal Industries, 1975, vol. 58, pp. 671-76.

62. S. Raveendra, S. Mishra, K.V. Mani Krishna, H. Weiland, and I. Samajdar: Metall. Mater. Trans. A, 2008, vol. 39A, pp. 2760-71.

63. P. Van Houtte: The MTM-FHM Software System, version 2, MTM-KULeuven, Brussels, Belgium, 1995.

64. H.J. Bunge: Texture Analysis in Materials Science, Butterworths, London, UK, 1982.

65. L.S. Toth and P. Van Houtte: Text. Microstruct., 1992, vol. 19, pp. $229-44$

66. S. Cicale, I. Samajdar, B. Verlinden, G. Abbruzzese, and P. Van Houtte: ISIJ Int., 2002, vol. 42, pp. 770-78.

67. J. Hirsch and K. Lücke: Acta Metall., 1988, vol. 36, pp. 2863-62. 68. Y. Zhou and K.W. Neale: Acta Mater., 1994, vol. 42, pp. 2175-89. 69. A. Ray and B.J. Diak: Scripta Mater., 2010, vol. 62, pp. 606-09. 